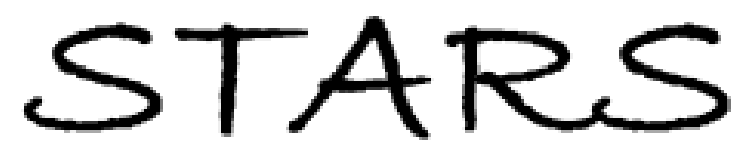

University of Central Florida

STARS

$1-1-2012$

\title{
Stand-off filament-induced ablation of gallium arsenide
}

\author{
Matthew Weidman \\ University of Central Florida \\ Khan Lim \\ University of Central Florida \\ Mark Ramme \\ University of Central Florida \\ Magali Durand \\ University of Central Florida \\ Matthieu Baudelet \\ University of Central Florida
}

See next page for additional authors

Find similar works at: https://stars.library.ucf.edu/facultybib2010

University of Central Florida Libraries http://library.ucf.edu

This Article is brought to you for free and open access by the Faculty Bibliography at STARS. It has been accepted for inclusion in Faculty Bibliography 2010 s by an authorized administrator of STARS. For more information, please contact STARS@ucf.edu.

\section{Recommended Citation}

Weidman, Matthew; Lim, Khan; Ramme, Mark; Durand, Magali; Baudelet, Matthieu; and Richardson, Martin, "Stand-off filament-induced ablation of gallium arsenide" (2012). Faculty Bibliography 2010s. 3472. https://stars.library.ucf.edu/facultybib2010/3472

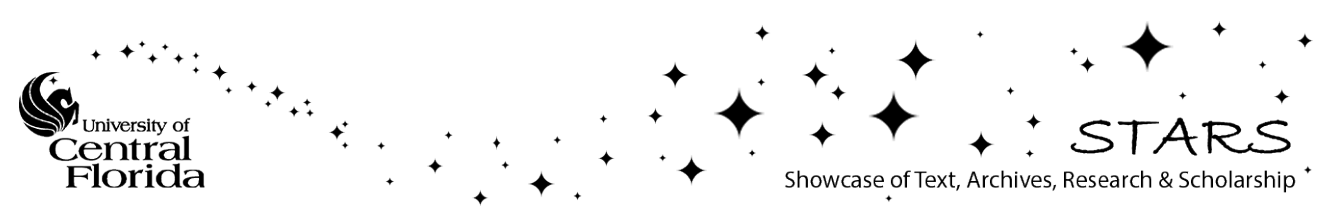




\section{Authors}

Matthew Weidman, Khan Lim, Mark Ramme, Magali Durand, Matthieu Baudelet, and Martin Richardson 


\section{Stand-off filament-induced ablation of gallium arsenide}

Cite as: Appl. Phys. Lett. 101, 034101 (2012); https://doi.org/10.1063/1.4734497

Submitted: 05 June 2012 . Accepted: 21 June 2012 . Published Online: 16 July 2012

Matthew Weidman, Khan Lim, Mark Ramme, Magali Durand, Matthieu Baudelet, and Martin Richardson

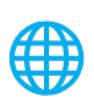

\section{ARTICLES YOU MAY BE INTERESTED IN}

Long-distance remote laser-induced breakdown spectroscopy using filamentation in air Applied Physics Letters 85, 3977 (2004); https://doi.org/10.1063/1.1812843

Femtosecond laser-induced periodic surface structures

Journal of Laser Applications 24, 042006 (2012); https:/ / doi.org/10.2351/1.4712658

Understanding the advantage of remote femtosecond laser-induced breakdown spectroscopy of metallic targets

Journal of Applied Physics 101, 033124 (2007); https://doi.org/10.1063/1.2437580

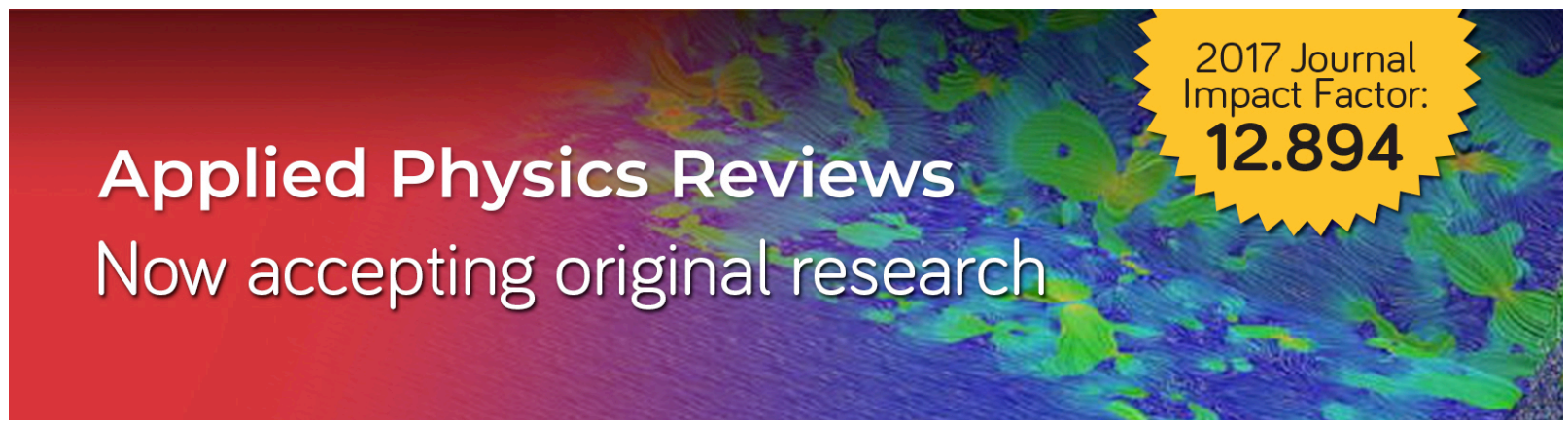




\title{
Stand-off filament-induced ablation of gallium arsenide
}

\author{
Matthew Weidman, Khan Lim, Mark Ramme, Magali Durand, Matthieu Baudelet, and \\ Martin Richardson \\ Townes Laser Institute, CREOL_The College of Optics and Photonics, University of Central Florida, 4000 \\ Central Florida Blvd., Orlando, Florida 32816, USA
}

(Received 5 June 2012; accepted 21 June 2012; published online 16 July 2012)

\begin{abstract}
Using femtosecond filaments for the ablation of GaAs in air, we have observed that the diameter and volume of the resulting ablation craters remained almost constant with propagation distance. This constant mass removal along the propagation of a filament in both focused and non-focused configurations is valuable for applications such as material processing and stand-off laser-ablation based spectroscopy. @ 2012 American Institute of Physics. [http://dx.doi.org/10.1063/1.4734497]
\end{abstract}

Filamentation of femtosecond laser pulses in air was first observed in $1995^{1}$ and has enabled applications, such as remote spectroscopy, ${ }^{2-4}$ laser material processing, ${ }^{5-7}$ filament-induced laser machining (FILM), ${ }^{8}$ and lightning control. ${ }^{9-13}$ Filamentation occurs when the input laser power exceeds a critical power threshold of $3.2 \mathrm{GW}$ in air for $100 \mathrm{fs}$ pulses at $800 \mathrm{~nm} .{ }^{14}$ Because the distance required for the onset of filamentation is usually on the order of several meters, depending on pulse characteristics, a lens is often used to help the collapse of the pulse.

Filaments have been shown to have the following characteristics: a central core diameter on the order of $100 \mu \mathrm{m}$ with an irradiance ${ }^{1}$ on the order of $10^{13} \mathrm{~W} / \mathrm{cm}^{2}$ that contains $5 \%-10 \%$ of the total energy ${ }^{15,16}$ - depending on the initial beam size and energy ${ }^{16}$ - and an energy reservoir that is more than 5 times the diameter of the core and contains approximately $50 \%$ of the beam energy. ${ }^{17}$ The filament core and energy reservoir are further surrounded by the less intense portion of the beam that contains the remaining energy. In contrast to focused femtosecond Gaussian beams, filaments present a unique irradiance profile, negligibly small numerical aperture and temporal pulse compression ${ }^{18-21}$ with potential temporal pulse splitting ${ }^{22,23}$ and steepening. ${ }^{24,25}$ These unique attributes of filamentation could lead to differences in laser material interaction and the resulting ablation.

This study aims to characterize the ablation of gallium arsenide (GaAs) by a single laser filament for remote applications such as laser-ablation-based spectroscopy and material processing. The reason for using GaAs was three-fold: (i) the interaction of femtosecond laser radiation with GaAs has been the topic of investigation since before laser filamentation in air was first reported, ${ }^{26-29}$ (ii) GaAs provided a smooth substrate that allowed for the characterization of single shot phenomena, and (iii) the slow rate of surface oxidation on GaAs has been characterized. ${ }^{30}$ For a GaAs sample ablated using a laser filament, we have compared the effects of focus-assisted filamentation, which are better known, with non-focused long distance filamentation which can be used for stand-off applications. We have found that the diameter and ablated crater volume remained fairly constant for both focused and non-focused filamentations within $12 \mathrm{~m}$ and $50 \mathrm{~m}$ ranges, respectively.
Filaments were generated using a commercial Ti:Sapphire CPA laser system (Tsunami + Spitfire, Spectra Physics) operated at $10 \mathrm{~Hz}$ and capable of producing $25 \mathrm{~mJ}$ pulses measured with a pyroelectric energy meter $(Q E-25+$ Solo II, Gentec), with a pulse duration of 45 fs measured by FROG (Model 8-20, Swamp Optics). ${ }^{31}$ This system was used to generate filaments within a $12 \mathrm{~m}$ range and a $50 \mathrm{~m}$ range. Within the $12 \mathrm{~m}$ range, the laser was operated with minimal chirp at $7.6 \pm 0.2 \mathrm{~mJ}$ pulse energy. Filaments were generated along a $6.6 \mathrm{~m}$ optical rail using a $10 \mathrm{~m}$ focal length dielectric mirror that was illuminated $1^{\circ}$ off-axis. Within the $50 \mathrm{~m}$ range, $21.5 \mathrm{~mJ}$ pulse energy was used (3.7\% RMS and $21.5 \%$ PTP (peak to peak) fluctuations) without external focusing optics. The pulses were chirped, by detuning the compressor, to prevent the onset of filamentation until after the beam steering optics. The initial pulse duration was approximately $500 \mathrm{fs}$. This was estimated by comparing the semiempirical formula for propagation distance required for collapse $^{14,32,33}$ and the distance for the beam to start filamenting, because it was outside the measureable range of our FROG (i.e., more than $180 \mathrm{fs}$ ).

The samples utilized were double-side-polished nondoped GaAs (llll 100$)$ wafers (ATX, Inc.) mounted with the surface perpendicular to the filamentation axis. In each sample position, a single filament was used for ablation and the sample was translated to a fresh surface for the next ablation; therefore, at each axial position along the filament, ablation statistics could be determined over 15 independent shots.

Sample metrology was performed primarily using an optical microscope (BX-51, Olympus) and a white-light interferometric microscope (WIM) (Newview 6300, Zygo). The optical surface profilometry results were verified using a surface contact profilometer (AlphaStep 200, Tencor).

The ablation crater on GaAs that resulted from femtosecond-filament irradiation (Fig. 1) had a diameter of approximately $470 \mu \mathrm{m}$. The sharp crater edges were characteristic of the femtosecond ablation of semiconductors ${ }^{34}$ and the crater presented little debris or heat influenced zones. Crater analysis using WIM, with micron transverse resolution limited by $10 \times$ optical objective and nanometer depth resolution, allowed for the retrieval of crater diameter and volume. When ablated by the filament within the $12 \mathrm{~m}$ range, the diameter and volume of the resulting craters remained 


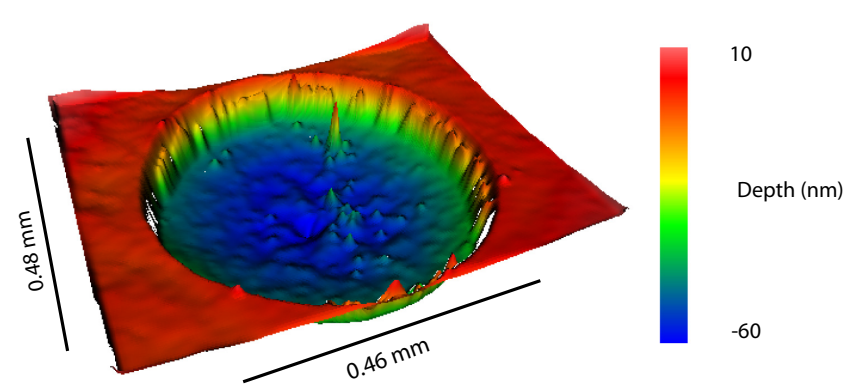

FIG. 1. 3D representation of an ablation crater, measured using WIM. The ablation crater resulted from a single shot at a distance of $15 \mathrm{~m}$ and without external focusing. False colormap represents the crater depth (linear scale).

constant (Fig. 2). The average crater diameter was $412 \mu \mathrm{m}$ with $5.1 \%$ relative standard deviation (RSD) and crater volume was $7600 \mu \mathrm{m}^{3}$ with $6.8 \%$ RSD. Samples were ablated every $40 \mathrm{~cm}$, for sample-to-focusing-mirror distances between $5.2 \mathrm{~m}$ and $12.8 \mathrm{~m}$. Under these conditions, the evolution of filamentation was clearly apparent. Filamentation occurred from approximately $6 \mathrm{~m}$ up to $11 \mathrm{~m}$, measured with respect to the focusing mirror; therefore, filamentation initiated by focusing $(f=10 \mathrm{~m})$ resulted in constant ablation well beyond the Rayleigh range.

Within the $50 \mathrm{~m}$ range (Fig. 3), no external focusing optics were used and, therefore, filamentation resulted from self-focusing alone. Distances were measured with respect to the last beam steering mirror, approximately $5 \mathrm{~m}$ from the laser output. Shot-to-shot fluctuations in the location of filament formation/discontinuation along the axis, coupled with shot-to-shot energy fluctuations and turbulence along the propagation resulted in larger error bars (Fig. 3) when com-
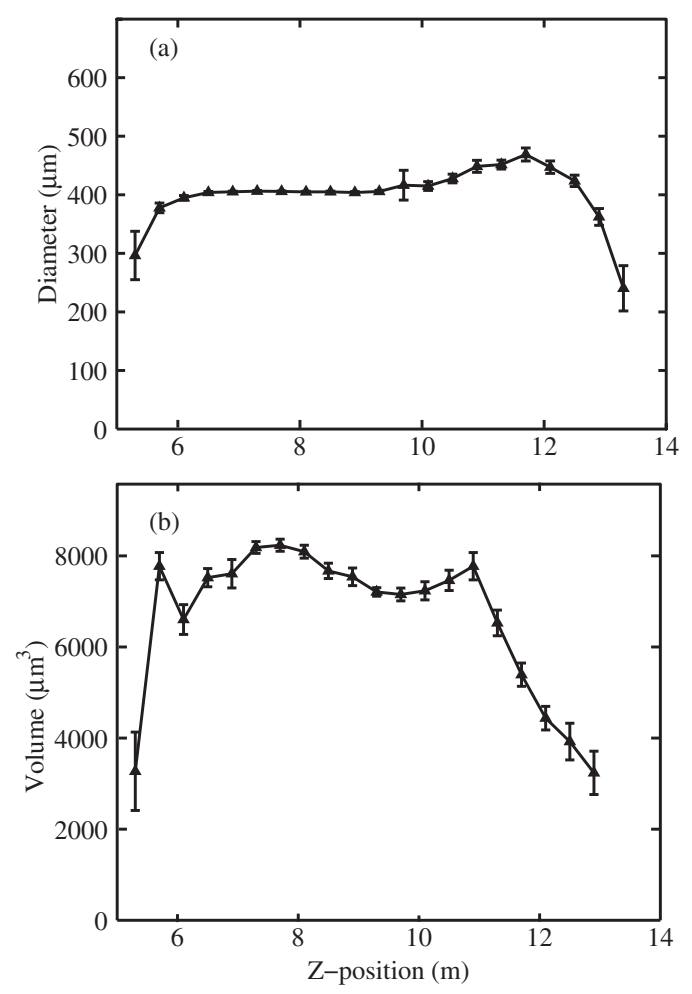

FIG. 2. Results from $12 \mathrm{~m}$ range: (a) Filament induced ablation crater diameter as a function of distance. (b) Ablated volume as a function of distance. Error bars represent the standard deviation evaluated over 15 measurements.
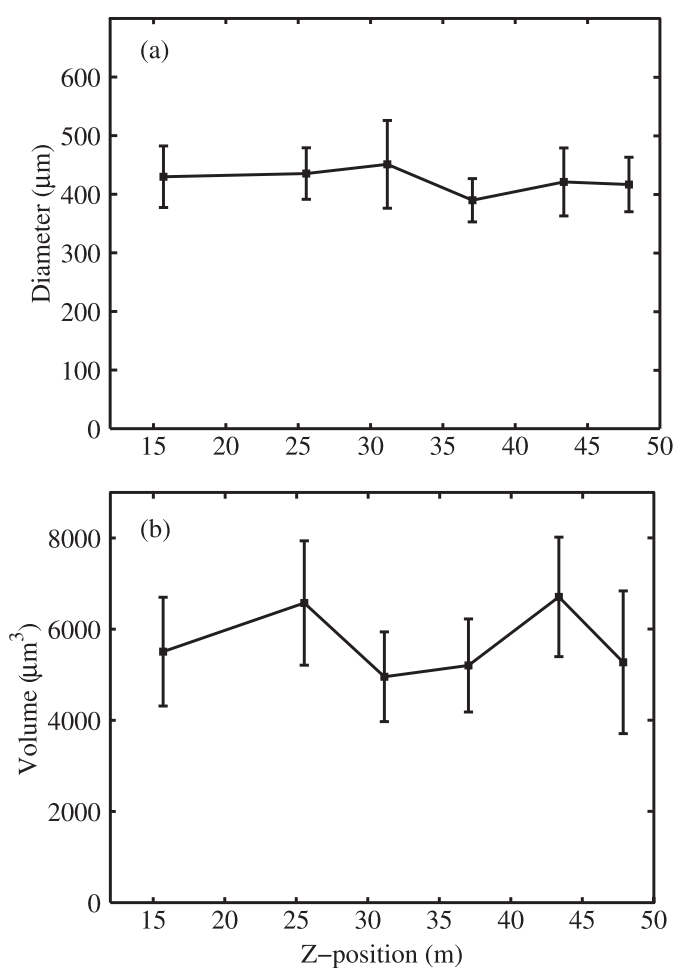

FIG. 3. Results from $50 \mathrm{~m}$ range: (a) Diameter of filament induced ablation crater as a function of distance. (b) Ablated volume as a function of distance. Error bars evaluated over 15 measurements.

pared with the focus-assisted-filamentation within the $12 \mathrm{~m}$ range (Fig. 2). Non-focused filamentation resulted in craters with an average diameter of $410 \mu \mathrm{m}$ with $27 \%$ RSD and volume of $5800 \mu \mathrm{m}^{3}$ with $45 \% \mathrm{RSD}$. The small decrease in crater volume for non-focused filamentation (Fig. 3(b)) versus focus-assisted-filamentation (Fig. 2(b)) suggests an irradiance difference between focused and non-focused configurations and is consistent with the previously reported dependence of filament plasma density and modeled fluence on lens focal length. ${ }^{35}$ However, over a propagation distance of $35 \mathrm{~m}$ (Fig. 3), the crater diameter and volume remained quite constant, and the ablative power was remakably similar to controlled filamentation using external focusing within a laboratory environment (Fig. 2).

For 100 fs pulses, the ablation threshold of crystalline GaAs has commonly been reported ${ }^{36,37}$ as between 175 $\mathrm{mJ} / \mathrm{cm}^{2}$ and $214 \mathrm{~mJ} / \mathrm{cm}^{2}$. In both filamentation conditions presented here, $50 \mathrm{~m}$ range non-focused and $12 \mathrm{~m}$ range focus-assisted filamentation, the ablation craters were larger in diameter than the approximately $100 \mu \mathrm{m}$ filament core. ${ }^{1,33}$ This suggests that the energy reservoir (region surrounding the filament) also exceeded the ablation threshold and remained constant during the filamentation process. These experimental observations agree with simulations ${ }^{38}$ for the filament fluence at radial distances of a few hundred microns, reported as being greater than $170 \mathrm{~mJ} / \mathrm{cm}^{2}$. Therefore, the energy reservoir should also be considered for filament induced ablation.

For focus-assisted filamentation, the crater volume remained approximately constant at $7600 \mu \mathrm{m}^{3}$ over $5 \mathrm{~m}$ of propagation and for non-focused filamentation, the crater volume remained about $5800 \mu \mathrm{m}^{3}$. As the density of GaAs is 
$5.136 \mathrm{~g} / \mathrm{cm}^{3}$, the removed mass within these two regimes was about $39 \mathrm{ng}$ and $30 \mathrm{ng}$, respectively. ${ }^{39}$ For stand-off chemical analysis using filamentation, material sampling on the order of $30 \mathrm{ng}$ is within the usable range for atomic emission spectroscopy. ${ }^{40}$

In conclusion, we have presented a quantitative comparison between focus assisted filamentation over a range of $12 \mathrm{~m}$ and non-focused filamentation over a $50 \mathrm{~m}$ range. We have shown that in both cases the ablation was similar. The importance of the energy reservoir in the interaction of laser filamentation with materials was clearly demonstrated by the formation of craters with larger diameter than the filament core.

Within the regime of non-focused filamentation, which has previously been reported for propagation over kilometer distances, this quasi constant material sampling with each shot should have important implications for stand-off spectroscopy and material processing applications.

This work was funded under the AFOSR-JTO Multidisciplinary Research Initiative FA95501110001 "Fundamental studies of Filamentation Interaction" and the State of Florida.

${ }^{1}$ A. Braun, G. Korn, X. Liu, D. Du, J. Squier, and G. Mourou, Opt. Lett. 20, 73 (1995).

${ }^{2}$ P. Rohwetter, K. Stelmaszczyk, L. Wöste, R. Ackermann, G. Méjean, E. Salmon, J. Kasparian, J. Yu, and J. P. Wolf, Spectrochim. Acta, Part B 60, 1025 (2005).

${ }^{3}$ J. F. Daigle, G. Méjean, W. Liu, F. Théberge, H. L. Xu, Y. Kamali, J. Bernhardt, A. Azarm, Q. Sun, and P. Mathieu, Appl. Phys. B: Lasers Opt. 87, 749 (2007).

${ }^{4}$ H. L. Xu, G. Méjean, W. Liu, Y. Kamali, J. F. Daigle, A. Azarm, P. T. Simard, P. Mathieu, G. Roy, and J. R. Simard, Appl. Phys. B: Lasers Opt. 87, 151 (2007).

${ }^{5}$ K. Yamada, W. Watanabe, T. Toma, K. Itoh, and J. Nishii, Opt. Lett. 26, 19 (2001).

${ }^{6}$ A. Couairon, L. Sudrie, M. Franco, B. Prade, and A. Mysyrowicz, Phys. Rev. B 71, 125435 (2005).

${ }^{7}$ S. Tzortzakis, L. Sudrie, M. Franco, B. Prade, A. Mysyrowicz, A. Couairon, and L. Bergé, Phys. Rev. Lett. 87, 213902 (2001).

${ }^{8}$ D. Kiselev, L. Woeste, and J. P. Wolf, Appl. Phys. B: Lasers Opt. 100, 515 (2010).

${ }^{9}$ J. Kasparian and J. P. Wolf, in Progress in Ultrafast Intense Laser Science, edited by A. Giulietti, K. Yamanouchi, and K. Ledingham (Springer, 2010), Vol. 98, pp. 109.

${ }^{10}$ R. Ackermann, G. Méchain, G. Méjean, R. Bourayou, M. Rodriguez, K. Stelmaszczyk, J. Kasparian, J. Yu, E. Salmon, and S. Tzortzakis, Appl. Phys. B: Lasers Opt. 82, 561 (2006).

${ }^{11}$ D. Comtois, C. Y. Chien, A. Desparois, F. Génin, G. Jarry, T. W. Johnston, J. C. Kieffer, B. La Fontaine, F. Martin, and R. Mawassi, Appl. Phys. Lett. 76, 819 (2000).
${ }^{12}$ H. Pépin, D. Comtois, F. Vidal, C. Y. Chien, A. Desparois, T. W. Johnston, J. C. Kieffer, B. La Fontaine, F. Martin, and F. A. M. Rizk, Phys. Plasmas 8, 2532 (2001).

${ }^{13}$ J. C. Diels, R. Bernstein, K. E. Stahlkopf, and X. M. Zhao, Sci. Am. 277, 50 (1997).

${ }^{14}$ J. Marburger, Prog. Quantum Electron. 4, 35 (1975).

${ }^{15}$ H. R. Lange, G. Grillon, J. F. Ripoche, M. A. Franco, B. Lamouroux, B. S. Prade, A. Mysyrowicz, E. T. J. Nibbering, and A. Chiron, Opt. Lett. 23, 120 (1998).

${ }^{16}$ A. Brodeur, C. Y. Chien, F. A. Ilkov, S. L. Chin, O. G. Kosareva, and V. P. Kandidov, Opt. Lett. 22, 304 (1997).

${ }^{17}$ W. Liu, F. Théberge, E. Arévalo, J. F. Gravel, A. Becker, and S. L. Chin, Opt. Lett. 30, 2602 (2005).

${ }^{18}$ S. Skupin, G. Stibenz, L. Bergé, F. Lederer, T. Sokollik, M. Schnürer, N. Zhavoronkov, and G. Steinmeyer, Phys. Rev. E 74, 56604 (2006).

${ }^{19}$ A. Mysyrowicz, A. Couairon, and U. Keller, New J. Phys. 10, 025023 (2008).

${ }^{20}$ A. Couairon, J. Biegert, C. P. Hauri, W. Kornelis, F. W. Helbing, U. Keller, and A. Mysyrowicz, J. Mod. Opt. 53, 75 (2006).

${ }^{21}$ C. P. Hauri, A. Trisorio, M. Merano, G. Rey, R. B. Lopez-Martens, and G. Mourou, Appl. Phys. Lett. 89, 151125 (2006).

${ }^{22}$ D. Faccio, M. A. Porras, A. Dubietis, F. Bragheri, A. Couairon, and P. Di Trapani, Phys. Rev. Lett. 96, 193901 (2006).

${ }^{23}$ A. C. Bernstein, T. S. Luk, T. R. Nelson, A. McPherson, J. C. Diels, and S. M. Cameron, Appl. Phys. B: Lasers Opt. 75, 119 (2002).

${ }^{24}$ H. Schröder, S. A. Hosseini, Q. Luo, and S. L. Chin, Opt. Commun. 266, 302 (2006).

${ }^{25}$ J. Kasparian, P. Béjot, and J. P. Wolf, Opt. Lett. 35, 2795 (2010).

${ }^{26}$ S. V. Govorkov, I. L. Shumay, W. Rudolph, and T. Schroder, Opt. Lett. 16, 1013 (1991).

${ }^{27}$ S. V. Govorkov, T. Schröder, I. L. Shumay, and P. Heist, Phys. Rev. B 46, 6864 (1992).

${ }^{28}$ K. Sokolowski-Tinten, H. Schulz, J. Bialkowski, and D. Linde, Appl. Phys. A: Mater. Sci. Process. 53, 227 (1991).

${ }^{29}$ P. Saeta, J. K. Wang, Y. Siegal, N. Bloembergen, and E. Mazur, Phys. Rev. Lett. 67, 1023 (1991).

${ }^{30}$ F. Lukes, Surf. Sci. 30, 91 (1972).

${ }^{31}$ M. Weidman, M. Baudelet, M. Fisher, C. Bridge, C. Brown, M. Sigman, P. J. Dagdigian, and M. Richardson, Proc. SPIE 7304, 73041G (2009).

${ }^{32}$ E. L. Dawes and J. H. Marburger, Phys. Rev. 179, 862 (1969).

${ }^{33}$ A. Couairon and A. Mysyrowicz, Phys. Rep. 441, 47 (2007).

${ }^{34}$ G. Herbst, M. Steiner, G. Marowsky, and E. Matthias, MRS Proc. 397, 69 (1995).

${ }^{35}$ F. Théberge, W. Liu, P. T. Simard, A. Becker, and S. L. Chin, Phys. Rev. E 74, 36406 (2006).

${ }^{36}$ A. Cavalleri, K. Sokolowski-Tinten, J. Bialkowski, and D. Von der Linde, Appl. Phys. Lett. 72, 2385 (1998).

${ }^{37}$ V. V. Temnov, Ph.D. dissertation, University of Duisburg-Essen, Essen, Germany, 2004.

${ }^{38}$ V. Y. Fedorov, O. V. Tverskoy, and V. P. Kandidov, Appl. Phys. B: Lasers Opt. 99, 299 (2010).

${ }^{39}$ D. R. Lide, CRC Handbook of Chemistry and Physics: A Ready-Reference Book of Chemical and Physical Data (CRC, 2004).

${ }^{40}$ L. Moenke-Blankenburg, Laser micro analysis (Pergamon Press, Oxford UK, 1986). 